DOI: $10.12957 /$ teias.2021.57855

\title{
IDENTIFICAÇÃO DO TALENTO MUSICAL NA ESCOLA
}

\author{
Fabiana Oliveira Koga \\ Rosemeire de Araújo Rangni
}

\section{Resumo}

Este artigo objetivou identificar estudantes com indicadores de talento musical de uma rede básica de ensino em uma cidade do interior paulista, por meio do uso do Protocolo para Screening de Habilidades Musicais (PSHM). A pesquisa foi de caráter exploratório e participaram 653 estudantes (352 meninas e 301 meninos) do ensino fundamental (anos iniciais) de escolas públicas e particulares. Os resultados indicaram que 16\% $(\mathrm{n}=104)$ dos participantes apresentaram indicadores de talento musical de modo inicial, no entanto, 11 (3 meninas e 8 meninos) (1,68\%) participantes se sobressaíram entre os 104. Conclui-se que o instrumento PSHM foi eficaz para identificar o talento musical, sendo uma via propícia para o reconhecimento dos estudantes e para receber o atendimento educacional especializado a que têm direito, conforme a legislação brasileira. O PSHM encontra-se em fase de construção, por isso, ainda serão necessárias as etapas de validação e fidedignidade. Ressalta-se que, por esse motivo, ele ainda não está disponível para o uso em geral.

Palavras-chave: educação especial; educação musical; talento musical; identificação.

\section{IDENTIFICATION OF MUSICAL TALENT A'T SCHOOL}

\begin{abstract}
This article aimed to identify students with musical talent indicators from a basic education network in a city in the inland of São Paulo, for this purpose the Protocol for Screening of Musical Skills (PSHM) was used. The research was exploratory and involved 653 students (352 girls and 301 boys) from elementary school (initial years) from public and private schools. The results indicated that $16 \%(\mathrm{n}=104)$ of the participants initially presented musical talent indicators, however, 11 (3 girls and 8 boys) (1.68\%) participants stood out among the 104. It is concluded that the PSHM instrument was effective in identifying musical talent, being a mean for the recognition of students, and for receiving the specialized educational assistance to which they are entitled, according to Brazilian law. The PSHM is under construction, so the stages of validation and reliability will still be necessary. It should be noted that, for this reason, it is not yet available for general use.
\end{abstract}

Keywords: special education; music education; music talent; identification.

\section{IDENTIFICACIÓN DEL TALENTO MUSICAL EN LA ESCUELA}

\section{Resumen}

Este artículo tuvo como objetivo identificar estudiantes con indicadores de talento musical de una red de educación básica en una ciudad del interior de São Paulo, por medio del uso del Protocolo de Proyección de Habilidades Musicales (PSHM). La investigación fue exploratoria e involucró a 653 estudiantes (352 niñas y 301 niños) de la escuela primaria (años iniciales) de escuelas públicas y privadas. Los resultados indicaron que el 16\% $(\mathrm{n}=104)$ de los participantes presentó inicialmente indicadores de talento musical, sin embargo, 11 (3 niñas y 8 niños) (1,68\%) participantes se destacaron entre los 104 . Se concluye que el instrumento PSHM fue efectivo en la identificación del talento musical, siendo un camino propicio para el reconocimiento de los estudiantes y para recibir la asistencia educativa especializada a la que tienen derecho, 
según la ley brasileña. El PSHM está en construcción, por lo que las etapas de validación y confiabilidad aún serán necesarias. Cabe destacar que, por esto motivo, aún no está disponible para uso general.

Palabras clave: educación especial; educación musical; talento musical; identificación.

\section{INTRODUÇÃO}

De acordo com a Lei de Diretrizes e Bases da Educação Nacional (LDBEN), Lei n. 9.394/96, estudantes com talento ${ }^{1}$ em alguma área do conhecimento humano integram, a partir da identificação ${ }^{2}$ e cadastramento no censo escolar o público da Educação Especial têm direito ao Atendimento Educacional Especializado (AEE), por meio da suplementação ou enriquecimento (BRASIL, 1996; BRASIL, 2011; FREITAS et al. 2012). De acordo com o Decreto n. 7.611, de 2011, a suplementação pode ocorrer nas escolas ou em centros especializados sempre respeitando o contraturno escolar (BRASIL, 2011), para além, a LDBEN orienta o cadastro no censo escolar ${ }^{3}$, o qual embasa a criação de políticas públicas e a distribuição de recursos destinados para a educação básica pelo Fundo de Manutenção e Desenvolvimento da Educação Básica e de Valorização dos Profissionais da Educação (FUNDEB).

Entre os estudantes talentosos estão aqueles que se destacam na área da música. Apesar da pouca valorização dessa área, no sistema escolar brasileiro, conforme apontou Fonterrada (2008), a legislação anuncia que as linguagens artísticas ${ }^{4}$ devem constituir o currículo escolar, sendo assim, é possível compreender que as áreas artísticas no ambiente escolar seriam uma oportunidade para a identificação de talentos, como argumentou Ilari (2013). A Lei n. 13.278/16 (BRASIL, 2016) é específica para o ensino das linguagens artísticas como componente curricular. Infelizmente, não são todas as escolas que contam com a disciplina de música.

Por esses motivos, empreende-se o questionamento: como identificar o talento musical, de modo preliminar, nas escolas de educação básica?

O objetivo dessa pesquisa foi identificar estudantes com indicadores de talento musical, a partir do uso do Protocolo para Screening de Habilidades Musicais (PSHM), de uma rede básica de ensino em uma cidade do interior paulista.

\section{FUNDAMENTAÇÃO TEÓRICA}

O talento musical pode se manifestar em diferentes pessoas, momentos históricos, culturas, classes sociais e etnias. Nesse sentido, quem nunca se deparou com crianças, jovens ou adultos com uma grande musicalidade e voz ou habilidade instrumental incomum ou inexplicável? Ou se surpreendeu com a precocidade musical de Amadeus Mozart, com a capacidade composicional/criativa de Villa Lobos e Luiz Gonzaga ou a habilidade interpretativa de Elis Regina, Milton Nascimento, Ney Matogrosso e muitos outros artistas?

\footnotetext{
1 A legislação brasileira utiliza o termo altas habilidades ou superdotação. No entanto, devido a opções teóricas relacionadas à música e à educação musical, este artigo faz uso do termo talento, com base em Teplov (1966), Haroutounian (2002), Kirnarskaya (2004), entre outros.

${ }^{2}$ Uma equipe multidisciplinar empreende diferentes instrumentos de avaliação para designar o talentoso (GAGNÉ, GUENTHER, 2012; RENZULLI, REIS, 2014).

3 Instituto Nacional de Estudos e Pesquisas Educacionais Anísio Teixeira (Inep). Disponível em http://inep.gov.br/web/guest/acesso-a-informacao .

${ }^{4}$ Música, dança, artes cênicas/teatro e artes visuais (plásticas).
} 
Gagné e Guenther (2012) assinalam que 10\% dos indivíduos, em um grupo comparável, podem manifestar talento para uma determinada área do saber humano. Complementarmente, Ilari (2013) argumenta que o talento musical em um grupo comparável reúne a combinação de precocidade, espontaneidade e habilidades específicas. A reunião desses aspectos faz com que a pessoa se destaque no grupo comparável. Winner (1996) anteriormente afirmou que o talento é a combinação dos seguintes indicadores: precocidade, autonomia para aprender (desvencilhar-se sozinho e fazer as coisas a seu modo) e interesse para o conhecimento, sede pelo saber. Robinson (2015), em consonância com os referidos autores supracitados, assinala a aprendizagem acelerada ou internalização rápida de conhecimentos musicais como indicadores de precocidade.

Nas pesquisas de Teplov (1966), o indivíduo talentoso vê/sente a música como um objeto estético e repleto de sentido; como uma história ou trilha, às vezes, baseada em fatos reais da vida. Os talentosos em música conseguem atingir o limiar da abstração extrema e colocam toda a libido na atividade musical, manifestando inclusive, a atenção criativa. A pessoa talentosa ouve os sons musicais como se cada um possuísse uma determinada nuance (cor), algo que esse autor denomina de audição colorida e pode manifestar o senso para os sons e batidas rítmicas (cognitivo), senso afetivo (estética) e criativo (imaginação). Na síntese elaborada por Teplov (1966), antes de ser artista é preciso ser músico e antes de ser intérprete é preciso manifestar o ouvido musical/musicalidade, além de saber ouvir a si mesmo e desfrutar da música produzida. Para o autor o talento musical é a combinação da aptidão - de elementar a superior - com a possibilidade de prática sistemática.

Kirnarskaya (2004) criou um esquema para demonstrar a interação entre os indicadores que compõem o talento musical, são eles: inteligência/habilidades musical, giftedness/criatividade e motivação, conforme ilustra a Figura 1.

Figura 1: Base do Talento Musical

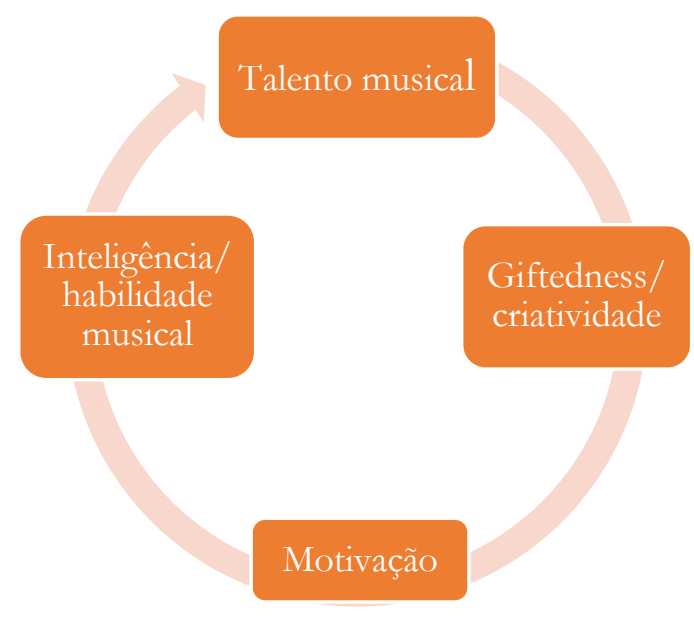

Fonte: Kirnarskaya (2013, p. 108)

Outros autores mencionam o talento musical em seus estudos: Gardner (1993) ao falar das inteligências múltiplas, sendo uma delas a musical; Ziegler e Heller (2002) ao sinalizar a musicalidade como um preditor do talento musical; Gordon (2015), na perspectiva teórica de Gagné e Guenther (2012), concluiu que o talento musical tem como matéria prima a aptidão, a qual 
se manifesta em diferentes níveis nos indivíduos e que a base da aptidão está na audiação ${ }^{5}$, memória, criatividade, inteligência e capacidade de fazer generalizações; e Galvão e Ribeiro (2014), os quais discutiram o quão profundo pode ser o vínculo estabelecido entre sujeito talentoso e o objeto, no tocante à música, um vínculo de amor que pode durar toda a vida.

Diante dos autores que se dedicaram ao talento musical também está Haroutounian (2002), que concluiu que o talento musical, metaforicamente, funciona como um spark (fagulha) no indivíduo. Ela ainda sinalizou a problemática de se trabalhar na investigação desse fenômeno complexo, principalmente, porque há uma variedade de termos sendo usados para designá-lo e as possibilidades do rastreamento pautadas nessas diferentes vertentes. Ademais, para a referida autora o fenômeno do talento é multiface e possui diferentes possibilidades para a sua apreensão. Apesar disso, Haroutounian $(2002,2013)$ insiste que a designação somente fará sentido se chegar ao enriquecimento e colocar ao indivíduo a oportunidade para o desenvolvimento. Para ela todos os termos expressam as nuances do fenômeno, porém a partir de ângulos/perspectivas diferentes, ela orienta como proceder na etapa de enriquecimento ${ }^{6}$ ou intervenção, que é a etapa mais importante.

Apesar desses pressupostos, as comunidades escolar e artística constantemente se perguntam: por que identificar o talento musical quando a música deveria ser para todos? (FONTERRADA, 2008). Ilari (2013) expõe o quanto é entediante para uma criança talentosa ter que aprender a música na sala de aula "A barata diz que tem" ou outras atividades típicas desse período escolar, quando ela pode ter uma sinfonia no pensamento e esperar do professor especialista o auxílio necessário com aspectos composicionais e outras dúvidas ou interesses.

Embora alguns professores, famílias e parte da sociedade possam ignorar a existência dessas crianças, jovens e adultos talentosos na área da música, Ilari (2013) assinala que eles precisam de incentivo específico, algo pontual e individualizado, apesar de sua reverberação no âmbito coletivo.

\section{MÉTODO}

Trata-se de uma pesquisa exploratória, a qual levanta informações a respeito de um objeto determinado mapeando também suas condições de manifestação e delimita o campo de trabalho (SEVERINO, 2007; MARCONI, LAKATOS, 2011). A seguir serão descritos os procedimentos empíricos da pesquisa.

Participaram 653 (352 meninas e 301 meninos) estudantes de escolas públicas e particulares, de um município do interior paulista, regularmente matriculados no ensino fundamental nos anos iniciais (do $1^{\circ}$ ao $5^{\circ}$ ano), denominados de $\mathrm{P} 1$ a $\mathrm{P}$ 653. O projeto de pesquisa percorreu todos os procedimentos éticos com a autorização do Comitê de Ética em Seres Humanos (CAEE 52337415.9.0000.5406).

\footnotetext{
${ }^{5}$ Termo constituído do inglês (audiation) por Edwin Gordon (2015) e traduzido para a Língua Portuguesa por Rodrigues e Gaspar, citados em Gordon (2015). O conceito audiação fundamenta-se na capacidade do sujeito de ouvir e compreender a música, de modo abstrato, em silêncio/pensamento, ou seja, trata-se do ouvido inverno (GORDON, 2015).

${ }^{6}$ Haroutounian (2002) elaborou instruções e etapas para o enriquecimento musical com base no modelo de Renzulli e Reis (2014), são elas: 1 - estimulação precoce (acendendo a fagulha / exploração geral); 2 - nutrição do talento (da fagulha para a chama / instrução); 3 - desenvolvimento profissional do artista (a chama / produção própria).
} 
O instrumento usado para identificar os estudantes foi o $\mathrm{PSHM}^{7}$, que é padronizado e composto por 127 itens, distribuídos e agrupados em oito dimensões, as quais são: timbre ( $\mathrm{n}=15$ pares de itens), altura $(n=18)$, melodia $(n=14)$, intensidade $(n=11)$, harmonia $(n=20)$, todas habilidades sensório-perceptivas; duração $(n=16)$, padrão-rítmico $(n=19)$ e agógica $(n=14)$, essas últimas consideradas habilidades rítmicas. Há um manual de instrução com os comandos escritos para serem lidos. A criança ouve os comandos e depois os exemplos (pares de áudios) como forma de instrução, depois, ela segue ouvindo cada par, um após o outro, e analisa se há formação diferente ou igual. As respostas podem ser registradas em uma folha ou na plataforma digital do PSHM. Há ainda dois tipos de questionários (Q1 e Q2) para caracterização dos participantes, sendo um para as crianças de $1^{\circ}$ ao $3^{\circ}$ ano e outro para o $4^{\circ}$ e $5^{\circ}$ ano (KOGA, 2019).

Quanto à coleta de dados se deu em dois formatos do PSHM ${ }^{8}$ : em sala de aula e no laboratório de informática. Para a versão física do PSHM, foi utilizado um fone de ouvido externo para cada criança e um equipamento de reprodução simultânea com a base principal acoplada ao computador. A aplicação no laboratório de informática estabeleceu a conexão com a internet para o acesso ao cadastro da escola e, consequentemente, ao dos estudantes e cada um ficou com um fone de ouvido externo. As respostas eram registradas em um campo específico de acordo com a dimensão e exercício.

Para a realização da análise e tratamento dos dados coletados, foram contabilizados os melhores resultados, sendo que os participantes considerados com indícios de talento musical foram aqueles que se encontraram iguais ou acima de 95 de pontuação para escola pública, e igual ou acima de 100 para escola particular ${ }^{9}$, em um universo de 127 itens. Essa estimativa se baseou nos estudos de Koga (2019), no percentual de 10\% sinalizado por Gagné e Guenther (2012), o índice recomendado por Gordon (2015) de 80 de escore e nas notas de corte dos instrumentos criados por Haroutounian (2002). Outro aspecto considerado para balancear os escores foi a presença do especialista da área da música, comum nas escolas da rede particular do local pesquisado.

\section{RESULTADOS E DISCUSSÃO}

É preciso destacar que o participante e a escola optam pela participação, o que pode alterar o n. No caso da rede particular houve um total de $n=242$ e na pública $n=411$.

Os resultados possibilitaram encontrar $\mathrm{n}=59$ estudantes com os melhores escores na rede privada e $\mathrm{n}=45$ na rede pública, com o índice de 16\%; margem que pode ser considerada relativamente boa para uma etapa de screening. Gagné e Guenther (2012) falam em 10\% em um grupo comparável, porém Gordon (2015) alerta para que não seja rigoroso em demasia porque as etapas posteriores mais avaliativas podem verificar possíveis falsos positivos e negativos.

Pensando na carência das escolas públicas brasileiras, principalmente, com relação à música, os argumentos de Fonterrada (2008) são verificáveis uma vez que a escola privada apresentou melhores índices, apesar do índice de corte ser maior. Isso leva à inferência da importância de ações

\footnotetext{
7 O PSHM está em processo de validação e fidedignidade para que possa ser disponibilizado para os professores interessados em colaborar com a identificação do talento musical.

${ }^{8}$ O material (kit) do PSHM foi criado em duas versões, vislumbrando garantir o acesso e usabilidade dos usuários, inclusive, acessibilidade de pessoas com deficiência (KOGA, 2019).

${ }^{9}$ A diferença de pontuação é recomendada por Gordon (2015) quando há diferenças significavas entre as escolas. As escolas públicas pesquisadas não contavam com especialistas em música ao passo que a rede particular sim. Esse tipo de diferença nos escores é bem utilizado pela área da psicologia na mensuração da inteligência ou da criatividade.
} 
educativas voltadas para a educação musical como disciplina ministrada por especialistas nas instituições escolares públicas como ocorre comumente na rede particular.

Ao realizar um crivo mais rigoroso, houve a busca por melhores resultados por turma. Como o PSHM conta com 127 itens, selecionaram-se os participantes que mais se aproximaram do valor estabelecido. Ao analisar os resultados da rede particular, o melhor participante foram: do primeiro ano (P20) atingiu o escore 101 (79,52\%), o do segundo ano (P77) alcançou 108 (85,03\%), o do terceiro ano (P102) pontuou 114 (89,76\%), o do quarto (P144) alcançou 117 (92,12\%) em escore e o participante 58 atingiu escore de 120 (94,48\%). Na rede pública P175 conseguiu escore 97 (76,37\%), no primeiro ano P207 atingiu escore 111 (87,40\%) do segundo ano, P224 do terceiro ano conseguiu escore 107 (84, 25\%), P349 do quarto ano obteve escore 110 (86,61\%) e, por fim, P274 e 291 obtiveram escores iguais 113 (88,97\%). Entre os participantes com maior destaque, na escola privada do primeiro ao terceiro ano, foram do sexo masculino. Do quarto ao quinto ano, na mesma rede, as participantes que se destacaram foram do sexo feminino, inclusive P58 foi a melhor participante da pesquisa no rank geral. Na rede pública, com exceção de P274, os demais participantes eram todos do sexo masculino.

Haroutounian (2002) discute também em sua pesquisa o quanto a área da música é basicamente formada por homens. A própria dedicação profissional da performance que muitas vezes colocam as mulheres na dura decisão entre a carreira profissional e a vida familiar com filhos. A área da música em sua vertente mais artística termina de modo semelhante aos esportes, exigindo a dedicação exclusiva e integral, por isso para muitas mulheres se torna complexo conciliar a vida pessoal e profissional.

Em âmbito mais geral, os resultados dos participantes com os melhores resultados evidenciam o quanto a vivência e o meio podem atuar positivamente na aptidão musical (matériaprima) das crianças. Teplov (1966) e Kirnarskaya (2004) discutiram massivamente a importância da vivência musical, inclusive, Gordon (2015) apresenta em sua pesquisa a importância do meio familiar na influência da musicalidade. No entanto, muitos podem receber influências musicais positivas e não atingirem bons resultados, sendo que esse fato não pode impedir o acesso à educação musical formal e sistematizada.

De acordo com Teplov (1966), ao mencionar a vida de Rimski-Korsakov ${ }^{10}$, foi categórico em afirmar que os indivíduos talentosos em música apresentam estado da alma / paixão, imaginação, emoção, afeto e sentimentos, mas que há algo comum nas pessoas com talento musical, pois elas têm ouvido expressivo e analítico ${ }^{11}$ para os sons e ritmos e percepção acurada e sensível. Essas constatações também são encontradas nas pesquisas de Kirnarskaya (2004). O ouvido expressivo e analítico compõe a musicalidade, por isso trata-se de uma premissa importante para suspeitar da existência do talento musical, ainda que preliminarmente. Ziegler e Heller (2002) assinalam que a musicalidade é um preditor do talento, devido a isso é recomendável ficar atento aos indicadores.

Ao analisar os resultados é possível observar que, na rede particular os índices melhoram com o passar dos anos escolares. A pontuação do participante do primeiro em relação ao do quinto da rede particular difere bastante. Isso ocorre porque, na concepção de Robinson (2015), há uma internalização da cultura musical. Qualquer criança passa por esse processo, no entanto, as crianças

${ }^{10}$ Nasceu na Rússia em 1844 e morreu em 1908. Foi militar, professor, maestro e compositor. É considerado um mestre da orquestração (TEPLOV, 1966).

${ }^{11}$ Ouvido expressivo - ter sensibilidade para perceber diferentes nuances sonoras e batidas rítmicas. O ouvido analítico configura-se na capacidade de perceber os sons e batidas, analisar, tomar decisão e realizar a síntese, ou seja, capacidade de analisar o que se ouve (KIRNARSKAYA, 2004). 
talentosas irão apresentar uma aprendizagem musical acelerada e sua internalização ocorrerá de modo rápido. Como esses participantes contam com as aulas de música, certamente, esses índices irão sofrer um crescimento ainda maior.

Com relação às escolas públicas, os achados coincidem com os de Gordon (2015). Ele argumenta em estabilização da percepção, inclusive, prevê o declínio por volta dos 11 e 12 anos. Os resultados obtidos nas escolas públicas corroboram as concepções tratadas por ele ao passo que nas escolas particulares não ocorrem de modo acentuado devido ao acesso a musicalização. A estabilidade da percepção é algo previsto, porém quando há o professor especialista estimulando as crianças, musicalmente, o decréscimo não é tão acentuado.

Nessa perspectiva, quem são esses participantes que se destacaram tanto? Os questionários possibilitaram averiguar que, na rede privada, P20 é alguém que gosta muito de música, não conta com músicos na família e aprecia músicas comerciais; P77 gosta muito de música, com pessoas em sua família envolvidas com a música e, também, aprecia a música comercial; P102 aprecia a música, é influenciada musicalmente por seus familiares e é fã de música midiática; P144 afirmou que gosta de música, tem influências em sua família e aprecia o gênero musical Pop e Jazz; P58 gosta de música, mas não tem músicos profissionais em sua família e é apreciador do Jazz e de MPB; P175 também gosta muito de música, tem influências musicais em casa e aprecia a música midiática; P207 gosta de música e alega ser influenciado musicalmente por sua família e aprecia música comercial americana; P107 gosta de música e recebe influência do Gospel e é seu repertório favorito; P349 afirmou gostar de música, disse não receber nenhuma influência musical e, no momento do preenchimento do questionário, alegou não se lembrar de seu gosto musical; P274 afirmou gosto pela música disse não ser influenciado musicalmente e não se lembrava de suas músicas preferidas; e P291 disse gostar de música, não é influenciado musicalmente por sua família e aprecia música comercial.

As influências musicais são importantes, porém não completamente determinantes certamente, brincadeiras, jogos e vivências variadas impactam o talento de modo positivo, sendo que conhecer a cultura é fundamental (FONTERRADA, 2008). Não restam dúvidas, na literatura especializada, que o ouvido e o sentir são portas de entrada para o conhecimento musical e, consequentemente, para o acesso ao talento (KIRNARSKAYA, 2004), no entanto não é a única porta de acesso. A aptidão, por exemplo, está relacionada à personalidade bem como à identidade, por isso, pode-se dizer que ela é individual e um indicador de talento assim como a criatividade, assinala Teplov (1996). Esse autor relata que o ouvido (acuidade apurada) se manifesta precocemente em pessoas com tendência ao talento musical e pode se manifestar desde os dois anos de idade e até antes, como também surge sem que ninguém se dê conta. Teplov fez essa constatação ao estudar filhos de músicos profissionais.

Devido às demandas em torno da identificação e intervenção para o desenvolvimento do talento musical, Haroutounian $(2002,2014)$ apresenta uma estrutura para a intervenção com crianças e jovens talentosos em música baseada no modelo de Renzulli e Reis (2014). Ela orienta desde a identificação, avaliação, a intervenção e trabalho longitudinal, entretanto, o material foi desenvolvido para a realidade norte-americana sem validação para o contexto brasileiro. Por essa razão, o PSHM foi construído e segue suas etapas de validação, assim como tem sido planejada a construção de outros materiais adicionais, pensando na etapa de enriquecimento.

No processo de enriquecimento, a criança talentosa deverá aprofundar o conhecimento musical e aprender diferentes técnicas, gêneros etc. O estudo do repertório, história da música, teoria, solfejo e desenvolvimento da musicalidade entre outros aspectos são alguns dos elementos de aprendizagem musical. Sugere-se que a criança identificada tenha orientação mais pontual, na 
qual a educação musical possa ser aliada importante no início, e, posteriormente, intervenções individualizadas devem ser pensadas. Neste sentido, ações como: projetos, conservatórios e instituições musicais constituem-se valiosos parceiros da escola, pois não é possível formar um músico profissional em grupo muito embora a música seja para todos. Por ser uma área de domínio específico, ela necessita de plano individual porque cada sujeito é único - o músico que executar um concerto de Chopin pode não conseguir um de Beethoven ou um soprano ligeiro não tem o mesmo repertório de um contralto (GAGNÉ, GUENTHER, 2012; GALVÃO, RIBEIRO, 2014). Por essas razões, após a identificação, crianças e jovens talentosos precisam de encaminhamento e/ou orientação especializada, argumentam Freitas et al. (2012) e Gagné e Guenther (2012) e Renzulli e Reis (2014). Os participantes dessa pesquisa foram orientados, por meio de devolutivas às famílias por escrito e foi oferecido curso de capacitação aos professores das escolas participantes (KOGA, 2019). Parte-se do pressuposto de que a identificação sem o enriquecimento não faz sentido, afinal, o atendimento educacional especializado é obrigatoriedade legal (BRASIL, 1996, 2011) e um meio de desenvolver os alunos com indicadores de talento musical.

\section{CONSIDERAÇÕES FINAIS}

As escolas brasileiras se abrem pouco para os conhecimentos artísticos, com isso, as classes sociais economicamente privilegiadas são mais beneficiadas, uma vez que as escolas da rede particular adotam o ensino de música em suas matrizes curriculares como disciplina complementar ou optativa, apesar, da impertinência como disciplina obrigatória pode-se dizer que esse é um fator positivo.

Talentosos estão ficando à margem da educação musical e, principalmente, da formação profissional individual, assim como há casos de compositores que têm uma realidade mais complexa. Em tempos em que se discute a inclusão, as pessoas talentosas pertencem ao público da Educação Especial, no entanto são pouco lembradas nas escolas.

A proposta apresentada de identificação do talento musical em crianças pequenas com o uso do PSHM vislumbra anseios de que a escola cumpra seu papel, principalmente nas públicas, muitas vezes desfavorecidas de estímulos para as artes. Entende-se como importante as ações da Educação Especial para identificar e atender adequadamente os estudantes que se destacam, caso contrário, no futuro não teremos como disfrutar de belas canções e interpretações e, tampouco descobriremos pessoas capazes de registrar suas marcas na história.

Nesse sentido, qual o futuro da música que queremos? Até quando deixaremos talentos musicais serem negligenciados em nossas escolas? O futuro é incerto, mas se incluir a música e as outras artes nas escolas, haverá um ambiente educacional mais valorizado e menos perdas de estudantes talentosos.

\section{Agradecimentos}

Pelo apoio e financiamento da Fundação de Amparo à Pesquisa do Estado de São Paulo - FAPESP.

\section{REFERÊNCIAS}

BRASIL. Ministério da Educação. Lei de Diretrizese e Bases da Educação Nacional. Brasília, 1996. 
BRASIL. Ministério da Educação. Decreto n. 7.611/2011. Dispõe sobre a educação especial, o atendimento educacional especializado e dá outras providências. Diário Oficial da União, Brasília: DF, 2011.

BRASIL. Ministério da Educação. Lei referente ao ensino de arte. Brasília, DF, 2016.

FONTERRADA, Marisa Trench de Oiveira. De tramas e fios: um ensaio sobre música e educação. São Paulo: Ed. UNESP; Rio de Janeiro: Funarte, 2008, p. 364.

FREITAS, Soraia Napoleão; NEGRINI, Tatiane; ROMANOWSKI, Caroline Leonhardt; HOSDA, Carla Beatriz Kunzler. Alunos com altas habilidades/superdotação: problematizando as tendências pedagógicas tendo em vista as práticas educacionais com estes alunos. Revista Teias, Rio de Janeiro, v. 14, n. 28, p. 195-209, 2012.

GAGNÉ, François; GUENTHER, Zenita Cunha. Desenvolvendo talentos: modelo diferenciado de dotação e talento - DMGT 2.0. In: MOREIRA, Laura Ceretta; STOLTZ, Tania. Altas habilidades/superdotação, talento, dotação e educação. Curitiba: Juruá, 2012, p. 19-44.

GARDNER, Howard. Frames of mind. New York: Perseus, 1993.

GALVÃO, Afonso; RIBEIRO, Anna Carolina Mendonça Lemos O. K. A prática traz a perfeição, mas o que sustenta a prática? Aspectos motivacionais e emocionais da aprendizagem expert de uma perspective psicanalítica. In: VIRGOLIM, Ângela Magda Rodrigues; KONKIEWITZ, Elisabete Castelon. Altas habilidades/superdotação, inteligência e criatividade. Campinas: Papirus, 2014, p. 309-334.

GORDON, Edwin Elias. Teoria de aprendizagem musical para recém-nascidos e crianças em idade pré-escolar. 4 ed. Lisboa: Fundação Calouste Gulbenkian, 2015.

HAROUTOUNIAN, Joanne. Kindling the spark: recognizing and developing musical talent. New York: Oxford University Press, 2002.

HAROUTOUNIAN, Joanne. Arts Talent ID: a framework for the identification of talented students in the arts. New York: Royal Fireworks Press, 2014.

ZIEGLER, Albert; HELLER, Kurt. Conceptions of giftedness from a meta-theoretical perspective. In: HELLER, Kurt; MONKS, Franz; STERNBERG, Robert; SUBOTNIK, Rena. International handbook of giftedness and talent. 2. ed. Londres: Elsevier Science, 2002, p. 3-22.

ILARI, Beatriz. Música na infância e adolescência: um livro para pais, professores e aficionados. Curitiba: Intersaberes, 2013.

KIRNARSKAYA, Dina. The natural musician: on abilities, giftedness and talent. New York: Oxford, 2004.

KIRNARSKAYA, Dina. How to predict professional success in music and beyond? Constructing universal talent's structure for the best vocational choices. Japão: The International Academy Forum, 2013. KOGA, Fabiana Oliveira. Protocolo para Screening de Habilidades Musicais. 2019. 250f. Tese (Doutorado em Educação) - Faculdade de Filosofia e Ciências, Universidade Estadual Paulista, Marília. 2019.

MARCONI, Marina de Andrade; LAKATOS, Eva Maria. Técnicas de pesquisa: planejamento e execução, amostragens e técnicas de pesquisa, elaboração, análise e interpretação de dados. 7. ed. São Paulo: Atlas, 2011.

RENZULLI, Joseph Sebastian; REIS, Sally Morgan. The schoolwide enrichment model: a comprehensive plan for education excellence. 3. ed. Connecticut: Creative Learning Press, 2014.

ROBINSON, Nancy. The early development of precocity. Gifted Child Quartely, Estados Unidos, v. 31, n. 4, p. 161-164, 2015. 
SEVERINO, Antonio Joaquim. Metodologia do trabalho cientifico. 23. ed. São Paulo: Cortez, 2007. TEPLOV, Boris M. Psychologie des aptitudes musicales. Paris: Press Universitaires de France, 1966. WINNER, Ellen. Crianças sobredotadas: mitos e realidades. Porto Alegre: Artmed, 1996.

Submetido em fevereiro de 2021 Aprovado em maio de 2021

\section{Informações das autoras}

Fabiana Oliveira Koga

Faculdade de Ensino Superior do Interior Paulista (FAIP)

E-mail: fabianapsicopedagogiamusical@gmail.com

ORCID: https://orcid.org/0000-0002-4646-1537

Link Lattes: http://lattes.cnpq.br/2374819863188673

Rosemeire de Araújo Rangni

Universidade Federal de São Carlos (UFSCar)

E-mail: rose.rangni@ufscar.com

ORCID: https://orcid.org/0000-0002-8752-9745

Link Lattes: http://lattes.cnpq.br/6399149504309769 